\title{
Chemical and Mechanical Actions of Drugs Active Group Used in COVID-19 Treatment
}

\author{
Suhayla K. Mohammed ${ }^{1}$, Mzahim M. Taha ${ }^{2}$ and Ekhlass M. Taha ${ }^{3}$ \\ ${ }^{1}$ College of Agriculture, University of Baghdad, Al-Jadriya, Baghdad, Iraq \\ e-mail: suhayla_81@yahoo.com \\ ${ }^{2}$ Kirkuk University, 36001 Kirkuk, Iraq \\ Consultant Orthopedic and Spine Surgeon - Erbil International Hospital \\ e-mail:dr.muzahem@yahoo.com \\ ${ }^{3}$ Department of Chemistry, College of Science for Women, University of Baghdad, Al-Jadriya, 10071 \\ Baghdad, Iraq \\ e-mail: ekhlassch@yahoo.com; ikhlasmb_chem@csw.uobaghdad.edu.iq
}

\begin{abstract}
With the new global outbreak of the novel COVID-19, control and treatment has become critical. There is no medication proven to be effective for the treatment of severe acute respiratory syndrome which is caused by COVID-19 according to the World Health Organization (WHO) reports. Most studies that have been done on this time are clinical trials. Those studies used several drugs like lopinavir, ritonavir, nebulized alphainterferon and, aminoquinolines.

The mechanism of action is not well known so far. This review studies the metabolites of the tested drugs with different kinds of the viral membrane which merging proteins based on mechanical criteria.
\end{abstract}

\section{Introduction}

The world has seen the existence of new disease caused by virus. The disease is named coronavirus disease 2019 (COVID-19), which develop as a results of infection

Received: September 1, 2021; Revised: September 21, 2021; Accepted: September 23, 2021

Keywords and phrases: COVID-19, drugs active group, mechanical action, lopinavir.

Copyright (C) 2021 the authors. This is an open access article distributed under the Creative Commons Attribution License, which permits unrestricted use, distribution, and reproduction in any medium, provided the original work is properly cited. 
with virus named severe acute respiratory syndrome coronavirus 2 (SARS-COV-2) [1]. To date there is no treatment for this novel virus, some clinical trials focused on some medications which have been used for treating other diseases.

The attention goes through chloroquine and hydroxychloroquine, these two chemicals compounds have been found to be efficient to treat or lower the viral symptoms [2]. Chloroquine with the formula $\mathrm{C}_{18} \mathrm{H}_{26} \mathrm{ClN}_{3}$ and molecular weight 319.9 $\mathrm{g} / \mathrm{mole}$ has two active groups Aminoquinoline and Chlorine [3]. The way of involvement of active groups in inhibits viral cell fusion or replication of viral components is not clear. Researches give a hand to reach virus knowledge update. Since information about this new virus is rapidly evolving. So the most common suggested way to inhibit viral action is cell viral diffusion through receptors action. So this review discusses the possibility of inhibit SARS-COV-2 action depending on host cell receptors and drugs actions.

\section{Mechanisms of SARS-COV-2 Membrane Fusion Proteins}

Three kinds of viral membrane fusion are reported class I fusion proteins, class II fusion proteins and class III fusion proteins [4]. Also there are at least four various mechanisms by which viral fusion proteins can be a move to go through fusion inducing conformational changes, the first mechanism depends on low PH theory, the second mechanism depends on receptor binding, whereas the third one depends on combination of receptor binding followed by low PH, the last mechanism still partially characterized [5]. Coronavirus are classified as class I which are followed combination mechanism that depend on receptor binding followed by low $\mathrm{pH}$, Virus cell fusion is completed by one or more viral surface glycoproteins at the neutral $\mathrm{pH}$ or within an endosomal cell at low $\mathrm{pH}[6]$, viruses are started, by either interaction with host cell receptors or require low $\mathrm{pH}$. Coronavirus are arranging the entrance of human respiratory epithelial cells through interaction of spike glycoprotein which is the most important surface protein of coronavirus with cell surface receptor angiotensin-converting enzyme 2 (ACE2) [6]. There are two regions in spiky glycoprotein one for host cell receptor S1 and the other is for membrane fusion S2. From the four structural coronaviruses proteins (spike (S) glycoprotein, envelope (E) protein, membrane (M) protein, and nucleocapsid (N) protein) the spike glycoprotein considered as a key target for treatment and diagnostics [7-8]. Angiotensin-converting enzyme 2 is mono-carboxypeptidase and 
metalloenzyme with a single zinc binding domain HEXXH. It is homologous to the active sites ACE. Also, it is located as a coenzyme on the surface of endothelial and other cells. So, ACE2 might be a potential goal for therapeutic mediation.

\section{Aminoquinolines as a Treatment of COVID-19}

Some quinine compounds have been investigated as SARS-CoV-2 medication. Chloroquine and hydroxychloroquine the most common quinine that have been used for SARS-CoV-2 [2-9-10].

Chloroquine is a 4-aminoquinoline, it is IUPAC name 4-N-(7-chloroquinolin-4-yl)-1$\mathrm{N}, 1-\mathrm{N}$-diethylpentane-1,4-diamine with the molecular formula, $\mathrm{C}_{18} \mathrm{H}_{26} \mathrm{ClN}_{3}$ and the molecular weight is $319.9 \mathrm{~g} / \mathrm{mole}$. Whereas, hydroxychloroquine is a derivative of chloroquine, it is IUPAC name 2-[4-[(7-chloroquinolin-4-yl)amino]pentylethylamino] ethanol with molecular formula $\mathrm{C}_{18} \mathrm{H}_{26} \mathrm{ClN}_{3} \mathrm{O}$ and the molecular weight is $335.9 \mathrm{~g} / \mathrm{mol}$. The two compounds have been known as natural cinchona alkaloid and they have been investigated as antimalarial drugs. The action of the drugs depends on the active groups that present in compounds or on the way to inhibit the receptors. Chloroquine and hydroxychloroquine, both have quinine and chlorine as active groups, whereas the hydroxyl group present only in hydroxychloroquine, each of chloroquine or hydroxychloroquine are racemic mixtures. Chloroquine has hydrogen bond acceptors count 3 and hydrogen bond donors count 1 . Whereas hydroxychloroquine has hydrogen bond acceptors count 4, and hydrogen bond donors count 2 [11-12-13]. Chloroquine and hydroxychloroquine are membrane-soluble weak bases. They are works by inters into the lysosomes within the malarial parasite. There is a vacuum inside the cell, sheltered by a membrane that acts as an inner stomach - they contain the enzymes and cofactors substantial for the parasite to safely break down haemoglobin and blocked the toxic haem waste products. Like the human stomach, the $\mathrm{pH}$ is brought down inside the lysosome than in the rest of the cell, and this acidic medium make chloroquine or hydroxychloroquine to become di-protonated (doubly positively charged), meaning it prevents chloroquine or hydroxychloroquine from leaving the vacuole via simple diffusion. Once inside, it causes a build-up of toxic haem that finally kills the parasite [14]. Recently chloroquine and hydroxychloroquine have been investigated for COVID19 treatment [15], whether those compounds influence or not on COVID-19 symptoms development it needs more trials, so what is interested in research, is about the infusing 
mechanism for the discussed compound in viral inhibition. One of the most common mechanisms depends on raising the $\mathrm{pH}$ in the host cell, which interferes with the virus's attempts to fusing the cell through lowering $\mathrm{pH}$. So if the $\mathrm{pH}$ changed, the virus cannot assemble, and if it cannot assemble, it cannot infect the host [15]. The other mechanism followed receptor binding inhibition since entrancing of coronavirus inside the cell required two key steps interfering with the glycosylation of angiotensin-converting enzyme 2 ACE2 the cellular receptor of SARS-CoV and blocking virus fusion with the host cell. Diminished terminal glycosylation of ACE2may moderates the binding efficiency between ACE2 on host cells and the SARS-CoV spike protein. Thus, the binding of the virus to the receptors on the cells is inhibited and infection is accordingly prohibited. What is interested to discuss is the combination between the receptor angiotensin-converting enzyme 2 and the involvement of the $\mathrm{pH}$, the optimum physiological $\mathrm{pH}$ for ACE2 action is 6.5, and what is well known is that CQ and HCQ considered as hydrogen bond accepter within the account (3, 4 respectively). So CQ and HCQ have the ability to inhibit ACE2 through raising the $\mathrm{pH}$. This mechanism could be complementary to the other mechanisms. In conclusion, we predict that HCQ and CQ can efficiently inhibit SARS-CoV-2 infection; also we assumed that drugs have good scope to fighting the disease. This potential awaits affirmation by clinical experiment.

\section{Lopinavir}

Most viruses encode proteases, which play an important role in the viral life cycle. Protease inhibitors (PIs) bind to the viral protease's substrate location in a competitive manner. This enzyme is responsible for the release of functional viral proteins after posttranslational proteolysis of a polyprotein precursor, allowing them to act correctly and individually in replication/transcription. Immature viral particles are produced as a result of inhibition [16].

Lopinavir is a protease inhibitor that targets HIV-1 protease with high specificity. Lopinavir is only available in the form of a combination with ritonavir. Abbott originally sold this combination in 2000 under the name Kaletra. Ritonavir is a powerful inhibitor of the enzymes involved in lopinavir metabolism, therefore taking it together enhances lopinavir exposure and antiviral effectiveness [17]. In China, PR was also mentioned as one of the options for the treatment of COVID-19 in the beginning of the pandemic mostly because it had shown some success against SARS and Middle East respiratory 
syndrome (MERS), and other therapeutic choices were limited [18-19]. A recent study found that triple therapy with interferon (IFN)-1b, ribavirin, and LPR could help individuals with mild-to-moderate COVID-19 recover more quickly. SARS4 has already been demonstrated to benefit from a combination of LPR and ribavirin. In addition, LPR can boost the effectiveness of IFN-1b against MERS in an animal model and in vitro [2021]. LPR has recently been shown to limit the replication of the severe acute respiratory syndrome coronavirus 2 (SARS-CoV-2) [22-23]. As a result, LPR could be effective in the treatment of COVID-19 patients.

\section{Interferon}

In the presence of viral infections, host cells produce and release interferons, which are cytokines. Interferons are divided into three types: type I, type II, and type III. Each type (I, III) caused by interaction between viral components and a variety of pathogen recognition receptors such as (retinoic acid inducible gene I like receptors, Toll like receptors) resulting in a complicated cascade of intracellular signaling events ending in interferon transcription and the development of the inflammatory response. Interferon type I (alpha, beta) and type III (lambda) can then be released into the surrounding tissue, activating cells that have their cognate receptor. Type I interferon was able to activate both hematopoietic and visceral cells in an autocrine and paracrine manner because type I interferon receptors are widespread, but type III IFNs are more restricted, to epithelial cells. Interferon mediate their activity by activating the JAK-STAT (Janus kinase and transcription protein activator signal transducer) signaling pathways in conjunction with other cellular elements (interferon-regulating factors, or IRFs), leading to the induction of hundreds of interferon-inducible genes and achieving an intrinsic cellular state of viral resistance [24]. IFN- $\alpha$, which is primarily produced by macrophages, and IFN- $\beta$, which is produced by bronchial epithelial cells in response to viral infection, are both Type I IFNs. They have the ability to bind to the surface of infected and surrounding cells and induce over 1,000 different IFN-inducible genes (ISGs), which impede virus protein trafficking, viral RNA synthesis, and virion assembly and release.

IFN-I is one of the first cytokines released after a viral infection. In most cell types, they are identified by the IFNAR receptor, which is found on the plasma membrane. The phosphorylation of transcriptional factors like STAT1 and their relocalization to the nucleus, where they activate interferon-stimulated genes, is induced when interferon is 
fixed on IFNAR (ISG). Most ISGs are involved in immune modulation, inflammation, and signaling. They interfere with viral replication and spread through several mechanisms such as slowing down the metabolism of cells or the secretion of cytokines that enhance adaptive immune activation. ISGs include (PRRs), which increase the sensitivity of the cell to pathogens, proteins that reduce membrane fluidity, inhibiting viral egress or membrane fusion, and antivirals that specifically inhibit one step of the viral cycle. As a result, IFN-I plays a critical role in antiviral defense. Because of their immunomodulatory effects [25]. IFN- has recently been proposed as a viable therapeutic method for COVID-19 disease, owing to the fact that the innate immune system produces IFN- as a first line of defense against viral infections. IFN-, on the other hand, might have immunoregulatory effects, resulting in pathogenic damage and uncontrolled inflammatory responses. There are 13 different human IFN subtypes that bind to the same receptor and regulate diverse antiviral and immunoregulatory effects, inducing diverse interferon-stimulated gene (ISG) expression. The varied degrees of inflammatory modulation may generate concerns about potential side effects such as enlarging inflammatory responses and worsening infection severity. As a result, investigating the mechanism of COVID-19 pathogenesis requires an examination of diverse IFN-subtype induction during SARS-CoV-2 infection [26].

\section{Conclusion}

In conclusion, we believe that these compounds can effectively prevent SARS-CoV2 infection, and that the medications have a strong chance of combating the disease.

\section{References}

[1] Prevention CfDCa (2020) coronavirus disease 2019 (COVID-19) - situation summary.

[2] P. Gautret, J-C. Lagier, P. Parola, V.T. Hoang, L. Meddeb, M. Mailhe, B. Doudier, J. Courjon, V. Giordanengo, V.E. Vieira, H.T. Dupont, S. Honoré, P. Colson, E. Chabrière, B. La Scola, J-M. Rolain, P. Brouqui and D. Raoult, Hydroxychloroquine and azithromycin as a treatment of COVID-19: results of an open-label non-randomized clinical trial, International Journal of Antimicrobial Agents (2020), 105949. https://doi.org/10.1016/j.ijantimicag.2020.105949

[3] T.C. Ho, Y.H. Wang, Y.L. Chen, W.C. Tsai, C.H. Lee, K.P. Chuang, Y.M. Chen, C.H. Yuan, S.Y. Ho, M.H. Yang and Y.C. Tyan, Chloroquine and hydroxychloroquine: efficacy in the treatment of the COVID-19, Pathogens. 10(2) (2021), 217. 
[4] L.J. Earp, S.E. Delos, H.E. Park and J.M. White, The many mechanisms of viral membrane fusion proteins, Current Topics in Microbiology and Immunology 285 (2005), 25-66. https://doi.org/10.1007/3-540-26764-6_2

[5] V.C. Chu, L.J. McElroy, V. Chu, B.E. Bauman and G.R. Whittaker, The avian coronavirus infectious bronchitis virus undergoes direct low-pH-dependent fusion activation during entry into host cells, Journal of Virology 80(7) (2006), 3180-3188. https://doi.org/10.1128/jvi.80.7.3180-3188.2006

[6] M. Hoffmann, H. Kleine-Weber, S. Schroeder, N. Krüger, T. Herrler, S. Erichsen, T.S. Schiergens, G. Herrler, N.-H. Wu, A. Nitsche, M.A. Müller, C. Drosten and S. Pöhlmann, SARS-CoV-2 cell entry depends on ACE2 and TMPRSS2 and is blocked by a clinically proven protease inhibitor, Cell 181 (2020), 271-280.

https://doi.org/10.1016/j.cell.2020.02.052

[7] N. Rezaei, COVID-19 and medical biotechnology, Avicenna J. Med. Biotechnol. 12(3) (2020), 139.

[8] N. Dong, X. Yang, L. Ye, K. Chen, EW-C. Chan, M. Yang and S. Chen, Genomic and protein structure modelling analysis depicts the origin and infectivity of 2019-nCoV, a new coronavirus which caused a pneumonia outbreak in Wuhan, China, 2020. bioRxiv:2020.2001.2020.913368. https://doi.org/10.1101/2020.01.20.913368

[9] T.Y. Hu, M. Frieman and J. Wolfram, Insights from nanomedicine into chloroquine efficacy against COVID-19, Nat. Nanotechnol. 15 (2020), 247-249.

https://doi.org/10.1038/s41565-020-0674-9

[10] Z. Sahraei, M. Shabani, S. Shokouhi and A. Saffaei, Aminoquinolines against coronavirus disease 2019 (COVID-19): chloroquine or hydroxychloroquine, International Journal of Antimicrobial Agents 55 (2020), 105945.

[11] K. Izawa, Y. Amino, M. Kohmura, Y. Ueda and M. Kuroda, 4.16 - Human-Environment Interactions - Taste, In: Liu H-W., Mander L. (eds.) Comprehensive Natural Products II, Elsevier, Oxford, 2010, pp. 631-671. https://doi.org/10.1016/B978-008045382-8.00108-8

[12] B.A. Aderibigbe and H.E. Mukaya, 7 - Nanobiomaterials Architectured for Improved Delivery of Antimalaria Drugs, In: Holban A.M., Grumezescu A.M. (eds.), Nanoarchitectonics for Smart Delivery and Drug Targeting, William Andrew Publishing, 2016, pp. 169-200. https://doi.org/10.1016/B978-0-323-47347-7.00007-0

[13] D. Zhou, S-M. Dai and Q. Tong, COVID-19: a recommendation to examine the effect of hydroxychloroquine in preventing infection and progression, The Journal of Antimicrobial Chemotherapy 75 (2020), 1667-1670. https://doi.org/10.1093/jac/dkaa114 
[14] D.C. Warhurst, J.C. Steele, I.S. Adagu, J.C. Craig and C. Cullander, Hydroxychloroquine is much less active than chloroquine against chloroquine-resistant Plasmodium falciparum, in agreement with its physicochemical properties, J. Antimicrob Chemother 52(2) (2003), 188-193. https://doi.org/10.1093/jac/dkg319

[15] J. Liu, R. Cao, M. Xu, X. Wang, H. Zhang, H. Hu, Y. Li, Z. Hu, W. Zhong and M. Wang, Hydroxychloroquine, a less toxic derivative of chloroquine, is effective in inhibiting SARS-CoV-2 infection in vitro, Cell Discovery 6 (2020), 16-16.

[16] K. Uzunova, E. Filipova, V. Pavlova and T. Vekov, Insights into antiviral mechanisms of remdesivir, lopinavir/ritonavir and chloroquine/hydroxychloroquine affecting the new SARS-CoV-2, Biomed Pharmacother. 131 (2020), 110668.

https://doi.org/10.1016/j.biopha.2020.110668

[17] R. Wu, L. Wang, HC.D. Kuo et al., An update on current therapeutic drugs treating COVID-19, Curr. Pharmacol. Rep. 6 (2020), 56-70.

https://doi.org/10.1007/s40495-020-00216-7

[18] Z. Wang, X. Chen, Y. Lu, F. Chen and W. Zhang, Clinical characteristics and therapeutic procedure for four cases with 2019 novel coronavirus pneumonia receiving combined Chinese and Western medicine treatment, BioSci. Trends 14 (2020), 64-68.

[19] B. Cao, Y. Wang, D. Wen, W. Liu, J. Wang, G. Fan et al., A trial of lopinavir-ritonavir in adults hospitalized with severe Covid-19, N Engl. J. Med. 382 (2020), 1787-1799.

[20] J.F. Chan, Y. Yao, M.L. Yeung, W. Deng, L. Bao, L. Jia, F. Li, C. Xiao, H. Gao, P. Yu, J.P. Cai, H. Chu, J. Zhou, H. Chen, C. Qin and K.Y. Yuen, Treatment with lopinavir/ritonavir or interferon - $\beta 1 \mathrm{~b}$ improves outcome of MERS-CoV infection in a nonhuman primate model of common marmoset, J. Infect. Dis. 212 (2015), 1904-1913. https://doi.org/10.1093/infdis/jiv392

[21] T.P. Sheahan, A.C. Sims, S.R. Leist, A. Schäfer, J. Won, A.J. Brown, S.A. Montgomery, A. Hogg, D. Babusis, M.O. Clarke, J.E. Spahn, L. Bauer, S. Sellers, D. Porter, J.Y. Feng, T. Cihlar, R. Jordan, M.R. Denison and R.S. Baric, Comparative therapeutic efficacy of remdesivir and combination lopinavir, ritonavir, and interferon beta against MERS-CoV, Nat. Commun. 11 (2020), 222. https://doi.org/10.1038/s41467-019-13940-6

[22] M. Costanzo, M.A.R. De Giglio and G.N. Roviello, SARS CoV-2: recent reports on antiviral therapies based on lopinavir/ritonavir, Darunavir/umifenovir, hydroxychloroquine, remdesivir, favipiravir and other drugs for the treatment of the new coronavirus, Curr. Med. Chem. 27 (2020), 4536-4541.

https://doi.org/10.2174/0929867327666200416131117 
[23] J. Lim, S. Jeon, H.Y. Shin, M.J. Kim, Y.M. Seong, W.J. Lee, K.W. Choe, Y.M. Kang, B. Lee and S.J. Park, Case of the index patient who caused tertiary transmission of coronavirus disease 2019 in Korea: the application of lopinavir/ritonavir for the treatment of COVID-19 pneumonia monitored by quantitative RT-PCR, J. Korean Med. Sci. 35 (2020), e79.

[24] L.H. Calabrese, T. Lenfant and C. Calabrese, Interferon therapy for COVID-19 and emerging infections: Prospects and concerns, Cleveland Clinic Journal of Medicine, 2020. https://doi.org/10.3949/ccjm.87a.ccc066

[25] E. Sallard, F. X. Lescure, Y. Yazdanpanah, F. Mentre and N. Peiffer-Smadja, Type 1 interferons as a potential treatment against COVID-19, Antiviral Research 178 (2020), 104791. https://doi.org/10.1016/j.antiviral.2020.104791

[26] L. Yang, J. Wang, P. Hui, T. O. Yarovinsky, S. Badeti, K. Pham and C. Liu, Potential role of IFN- $\alpha$ in COVID-19 patients and its underlying treatment options, Applied Microbiology and Biotechnology 105(10) (2021), 4005-4015.

https://doi.org/10.1007/s00253-021-11319-6 